\title{
PALABRAS QUE DEJAN HUELLA: VIOLENCIA EN LA ESCUELA A TRAVÉS DEL DISCURSO
}

\section{Elsa Piedad Cabrera Murcia*}

SÍNTESIS: El presente ensayo busca una reflexión sobre el fenómeno de la violencia en la escuela, a partir de una mirada al género discursivo - lenguaje- que se establece en la relación entre profesor y alumno. En este sentido. se plantea que la violencia no sólo se reduce a aquellos actos violentos visibles a nuestros ojos, sino también a aquellos que empiezan a ser «visibles» a nuestros oídos. Es decir, dejamos huella en el otro con nuestras acciones y con nuestras verbalizaciones, las cuales influyen en el desarrollo de la individualidad de cada uno de los niños y niñas que asisten a la escuela. De esta manera postulo que la estructura unitaria a través de la cual los niños y niñas se reconocen comosi mismos, es decir, su self, es afectada por los otros con quienes interactúa; y que el lenguaje plasmado en el discurso se presenta como el medio por el que ellos influyen en los demás, y, en este caso, el medio por el cual son influidos por los otros.

SÍNTESE: O presente ensaio busca uma reflexão sobre o fenômeno da violência na escola, a partir de um olhar no gênero discursivo linguagem - que se estabelece na relação entre professor e aluno. Neste sentido, se estabelece que a violência não só se reduz àqueles atos violentos visíveis aos nossos olhos, como também àqueles que começam a ser «visíveis» aos nossos ouvidos. Ou seja, deixamos marcas no outro com nossas ações e com nossas verbalizações, as quais influenciam no desenvolvimento da individualidade de cada um dos meninos e meninas que freqüentam a escola. Desta maneira, postulo que a estrutura unitária, através da qual os meninos e meninas se reconhecem como a si mesmos, ou seja, seu self, é afetada pelos outros com quem interagem; e que a linguagem plasmada no discurso se apresenta como o meio pelo qual eles

* Phd (c) Psicología, Pontificia Universidad Católica de Chile. 
influenciam os demais, e, neste caso, o meio pelo qual são influenciados pelos outros.

Uno de los interrogantes que actual mente cobra importancia en el ámbito de la escuela se refiere al tema de la violencia. Ahora bien, ¿qué es la violencia escolar? Intentar explicar qué se entiende por violencia escolar es complejo. La revisión de la literatura sobre el particular muestra una marcada tendencia a verla como un fenómeno que abarca distintas manifestaciones que comparten idéntico sustrato violento.

Por ejemplo, Olmedilla (2002) y Wallach (1996) exponen que, dentro del contexto escolar, se guardan en un mismo saco todas aquellas acciones que deslegitiman o que aminoran al otro. Las disrupciones en las aulas, los problemas de disciplina, el maltrato entre compañeros, el vandalismo, la violencia física, las agresiones, entre otras, se presentan como acciones violentas en las que los límites entre unas y otras no están claramente definidos, pero que remiten a un tipo particular de violencia: la violencia física o «visible a los ojos».

Sin embargo, otra perspectiva ha abierto paso a una nueva mirada de este fenómeno: la violencia «visible a los oídos». Con esta se hace referencia a la violencia que tiende a ser menos perceptible, pues no compromete ningún acto físico violento hacia el otro, sino a la que puede ejercerse a través del lenguaje, 0, como afirma Flores (2002), es aquella con la que se puede «agredir o aminorar al otro desde un determinado discurso». Bakhtin, en su libro The Problem of Speech Genres, escribió: "Las formas de lenguaje y las formas típicas de pronunciación, esto es, los géneros discursivos, entran en nuestra experiencia y en nuestra conciencia en cercana conexión con otro» (Bakhtin, 1986, p. 78), y, en este sentido, se podría afirmar que nuestra manera de conocer y de darle sentido al mundo, tanto interno como externo, ha estado siempre pregnado del lenguaje.

Con el lenguaje damos vida e intencionalidad a nuestras acciones, como también a las interacciones con el otro. Éstas pueden tener un tinte favorable o desfavorable, pero en ambos casos con ellas damos significado a nuestra vida. En tal sentido, y posicionados desde una mirada sociogenética, la mente estaría determinada socialmente, y estaríamos dando énfasis a la individualidad tanto como a la demostración de la naturaleza social de la persona (Valsiner y van der Veer, 2000).

Considerar la violencia «visible a los oídos» desde la perspectiva de un proceso dialógico, posiciona al lenguaje en un lugar estratégico 
para analizar dicho fenómeno, y, en consecuencia, se pueden extraer tres aspectos que nos permiten seguir el análisis:

- Las palabras no están desligadas de un contexto, sino que, por el contrario, se encuentran tejidas dentro de una red intersubjetiva en la que están inmersos diferentes actores que participan de dicha situación.

- Este mundo figurado que se presenta como un fenómeno histórico y social (Holland y otros, 1998, citado en Skinner y otros, 2001), está conformado por diferentes voces o sí mismos, con grados de estatus o de poder variados.

- Las voces con menor poder (niños y niñas) conforman sus identidades o sus propios self «dialógicamente, a través de la participación continuada con los otros actores» (Skinner y otros, 2001).

Consideremos el siguiente extracto de un pasaje del libro de Miller (1992), que ejemplifica cómo desde el discurso se puede ejercer un acto violento:

Al preguntar una vez a un maestro de escuela cómo había conseguido que los niños le obedecieran sin necesidad de golpes, me respondió: «trato de convencer a mis alumnos, a través de mi comportamiento, de que estoy actuando por su propio bien, y les demuestro mediante ejemplos y comparaciones que ellos serán los primeros perjudicados si no me obedecen. Además, ofrezco como recompensa que el más complaciente, obediente y aplicado en las horas de clase puede ser preferido a los demás. Les hago muchas más preguntas, les permito leer su composición en público, y les hago escribir en la pizarra lo que sea preciso copiar (p. 35$)^{1}$.

A partir de lo anterior, podría afirmarse que la escuela se constituye en el contexto en el que los niños y las niñas conforman su estructura unitaria ( self). Es decir, la estructura por la cual se reconocen como sí mismos, y, a la vez, por la que construyen su mundo externo. Como resulta evidente, este mundo externo se construye a partir de las relaciones intersubjetivas que se establecen cotidianamente a través del discurso. Bakhtin (1981) afirmaba que muchos de los discursos que se pronuncian en la vida diaria están cargados de significación psicológica

\footnotetext{
${ }^{1}$ Las cursivas son mías.
} 
que les atribuyen las personas que los producen, y que quienes los reciben lo hacen con un sentido y con un significado también psicológico. En otras palabras, el lenguaje es una herramienta primordial que influye en la configuración tanto del self como del espacio en el que se construye ese self.

Entonces, ¿cuál es el significado o el sentido que subyace en ese o en muchos de estos discursos que se emiten en el contexto escolar? ¿Cómo se legitima la violencia a través del discurso?

Enunciados como «estoy actuando por tu propio bien», «ellos serán los primeros perjudicados si no me obedecen», «el más complaciente, obediente y aplicado en las horas de clase puede ser preferido a los demás»; «...cómo quedó el otro después del golpe» etc., que con frecuencia se escuchan en las aulas y en los pasillos de nuestras escuelas del siglo XXI, se constituyen en discursos reproductores de patrones tradicionales (Milicic, 2002), como también de significaciones que «denigran la existencia del otro, lo rechazan o lo cosifican» (Barudy, 2000).

En este sentido, el planteamiento desde la semántica generativa de que «no se habla para construir frases sintácticas correctamente sino para decir algo, en donde lo estructurante no reside en la sintaxis sino en el significado, en la semántica» (Drucaroff,1997, p. 41), nos confirma el sentido $o$ el significado que pueden tener de trasfondo dichas palabras o enunciados, y que, como éstas - ya lo dijimos-, pueden llegar a constituirse en un acto violento en el que se pierde la concepción de persona, se deslegitima al otro, y, en consecuencia, se le reduce a la categoría de un objeto.

Así, los niños y las niñas «no son pizarras limpias en las que podamos escribir o dibujar» (Losada, 2002, p. 3) una estructura unitaria, aislada de un tiempo y de un espacio determinados, aspectos que le dan sentido a aquella. Por el contrario, al estar encarnados en un contexto histórico, poseen una «forma única de pararse en el mundo» (Milicic, 2002). Por tanto, la consecuencia inmediata es la construcción de dicha estructura unitaria desde una posición determinada, pero en relación con los otros. Es decir, el self se establece a partir de un proceso dialógico que se concibe como social (Hermans, Kempen y Loon, 1992).

El self dialógico es desafiado continuamente por preguntas, por desacuerdos, por conflictos y confrontaciones que le permiten ir constru- 
yendo su sentido de identidad personal, de tener una identidad separada de los otros, y de procesar cada una de las experiencias a las que se enfrenta (Hermans, 1996). Voces mucho más directas como: «eres inquieto», «qué desaplicado», «eres el más desordenado», entre otras, pueden estar llegando a sus mentes y constituirse, al igual que las anteriores, en «voces encarnadas en un mundo semiótico y cultural» (Skinner y otros, 2001). En ese sentido es relevante, dentro del contexto escolar, identificar no sólo aquellos actos que por presentarse visibles pueden considerarse violentos, sino también aquellas voces que pueden pasar desapercibidas a los ojos y a los oídos del sistema, pero que en el mundo interno de nuestros niños y niñas tienen eco y adquieren sentido en la constitución de su propio self.

Nos referimos a las expresiones que emitimos gracias a la capacidad humana que nos hace diferentes de los animales, y que nos ubican dentro de la escala evolutiva en una posición privilegiada: el lenguaje. Pero, al parecer, en muchas ocasiones estas voces o expresiones que pronunciamos transgreden el campo de la legitimidad del otro, violentando su «sí mismo». Drucaroff (1996) afirma que las voces de los otros siempre previas a la mía y siempre posteriores, no sólo señalan Ios límites físicos del enunciado, sino también delimitan su sentido. Éste último, por tanto, ha sido dado a partir de lo que ya se ha dicho, de las opiniones, de las confrontaciones, de los discursos almacenados sobre el mismo tema. Entonces sería sensato reflexionar sobre ¿qué uso le damos al lenguaje dentro del aula o en los pasillos de nuestras escuelas cuando nos relacionamos con los niños y las niñas?

¿Cuántas veces nuestro discurso ha generado en ellos una redefinición de su identidad sin que lográramos percibirlo? ¿Cuántas veces estas palabras cargadas de acentos valorativos y acompañadas de gestos sobrepasaron al otro?

Todo entra en nosotros como un discurso que orquestamos y que internalizamos en nuestra estructura unitaria. Esa estructura, construida socialmente a través de un proceso dialógico, es la que nos hace únicos e irrepetibles, la que nos permite diferenciarnos los unos de los otros, pero también la que nos ayuda a acercarnos a la especie humana. En su conformación, el lenguaje se configura como una herramienta que ayuda a la riqueza de dicha estructura, y que, con el correr de los tiempos, se ha convertido en un instrumento más efectivo que el látigo o que el castigo. 


\section{BIBLIOGRAFÍA}

BAKHTIN, M. (1986): Speech Genres and other late Essays, Austin, University of Texas Press.

- (1981): The Dialogic Imagination: Four Essays by M.M. Bakhtin, M. E. Holquist (ed.), C. Emerson y M. Holquist (trads.), Austin, University of Texas Press.

BARUDY, J . (2000): «Violencia agresiva y violencia ideológica en la fenomenología humana», en 0 . Vilches (ed.) Violencia en la cultura: riesgos y estrategias de intervención. (pp. 11-29). Santiago de Chile, Sociedad Chilena de Psicología Clínica.

DruCAROFF, E. (1996): Mijail Bajtín: La guerra de las culturas, Buenos Aires, Editorial Almagesto.

FLORES, L. (2002): «El fenómeno de la violencia en la escuela. Aproximación ética antropológica». <http://www.enlaces.cl/modulos/noticias/... / detalle_noticias.asp?id_noticia $=5357 \&$ esc $=$ generic $>$ [consulta: abr. 2005].

Hermans, H. (1996): «Voicing the Self: From Information Processing to Dialogical Interchange», Psychological Bulletin 119 (1), pp. 31-50.

Hermans, H.; KemPen, H., y LOON, R. (1992): «The Dialogical Self. Beyond Individualism and Rationalism», American Psychologist, 47 (1), pp. 23-33.

LOSADA, J. (2002): «¿Violencia en la escuela o violencia de la escuela?», en Revista Electrónica Interuniversitaria de Formación del Profesorado, 5 (4). <http:/l www. aufop. org/publica/reifp/artículo.asp?pid=211\&docid=912> [consulta: mar. 2005].

MILICIC, N. (2002): «Elaboración y evaluación de un programa audiovisual para fortalecer las competencias parentales mediante una alianza efectiva familia-escuela», presentación Coloquio, Escuela de Psicología, Santiago de Chile.

MILLER, A. (1992): Por tu propio bien. Raíces de la violencia en la educación del niño, Tusquets Editores (2.a edición).

OLmEDILLA, J . M. (2002): «Comportamiento antisocial en los centros escolares: Una visión desde Europa.», en Revista Iberoamericana de Educación, n.18, Madrid, OEI. <http://www. oei. org.co/oeivir/rie18a09.htm> [consulta: abr. 2005].

SKINNER, D.; VALSINER, J ., yHOLLAND, D. (2001): «Discerning the Dialogical Self: A Theoretical and Methodological Examination of a N epali Adolescent's Narrative», Forum Qualitative Social Research, 2 (3). <http://www.qualitative-research.net/fqs-texte/3-01/ 3-01skinneretal-e.htm> [consulta; mar. 2005].

VALSINER, J., YVEeR, R. van der (2000):The Social Mind. Construction of the Idea, Cambridge University Press.

WALLACH, L. (1996): «La violencia y el desarrollo de los niños». <http:// ericeece. org/pubs/digests/1996/viole96s.html> [consulta: mar. 2005]. 


\title{
REVISTA IBEROAMERICANA DE EDUCACIÓN
}

\author{
REGRESAR A ÍNDICE № 37
}

REGRESAR A PÁGINA INICIAL DE LA REVISTA

CONTACTAR 